\title{
A IMPORTÂNCIA DA EDUCAÇÃO SUPERIOR NA PERCEPÇÃO E COMPREENSÃO DE UNIVERSITÁRIOS DO CURSO DE EDUCAÇÃO FÍSICA SOBRE AS ALTERAÇÕES CLIMÁTICAS
}

\author{
Bruno Barbosa Rosa ${ }^{1}$ \\ Lucas Ribeiro Marques Campos de Oliveira ${ }^{2}$ \\ Daniel dos Santos ${ }^{3}$ \\ Roberta Bessa Veloso Silva ${ }^{5}$ \\ Ulisses Miranda Azeiteiro 4 \\ Monica de Andrade ${ }^{3}$
}

Resumo: Propósito - A importância da inserção da temática das alterações climáticas no ambiente educacional a fim de tornar a formação superior mais consciente e responsável na área da saúde e meio ambiente. Metodologia - $\mathrm{O}$ estudo foi baseado na aplicação de um questionário sobre alterações climáticas para avaliar a relação entre algumas variáveis qualitativas de interesse. Foi utilizado o teste exato de Fisher ao nível nominal de $5 \%$ de significância respaldado pelo de Qui-quadrado. Resultados - Apesar de a maioria dos universitários acreditar que as alterações climáticas estão acontecendo nesse momento eles consideram que são poucas as informações a respeito do tema, declarando que a inserção na grade curricular pode fazer diferença na formação.

Palavras-chave: Alterações Climáticas, Instituição de Ensino Superior, Educação Física.

${ }^{1}$ Docente na Universidade José do Rosário Vellano - UNIFENAS, Alfenas-MG; Mestre em Promoção de Saúde na Universidade de Franca - UNIFRAN, Franca-SP.

2 Doutorando em Promoção de Saúde na Universidade de Franca - UNIFRAN, Franca-SP.

${ }^{3}$ Docentes no curso de pós-graduação Stricto Sensu em Promoção de Saúde na Universidade de Franca - UNIFRAN, Franca-SP.

${ }^{4}$ Docente na Universidade de Aveiro, Aveiro, Portugal.

${ }^{5}$ Docente na Universidade José do Rosário Vellano - UNIFENAS, Alfenas-MG; Doutorado em Estatística e Experimentação Agropecuária na Universidade Federal de Lavras - UFLA. 


\section{Introdução}

A promoção da saúde deve levar em consideração dois aspectos; a complexidade da sociedade e a inter-relação entre o ambiente e os indivíduos que o habitam. Sendo assim, a saúde não pode ser considerada um conceito sem ligação com o ambiente uma vez que o elo entre a saúde do ser humano e o meio ambiente é inseparável.

Nesse contexto, o ambiente constitui a base para uma abordagem socioecológica da saúde. O impacto que as mudanças ambientais vêm causando na saúde está sendo acompanhado de forma sistemática principalmente pelas áreas de tecnologia, trabalho, produção de energia e urbanização. Esse acompanhamento é fundamental desde que seguido de ações que garantam benefícios para a saúde da população. Por isso, além de acompanhar a evolução das mudanças ambientais é necessário proteger o meio ambiente e conservar os recursos naturais como estratégia de promoção de saúde (BRASIL, 2002).

Em 1991 na cidade de Sundsvall na Suécia, foi realizada a terceira conferência internacional de promoção da saúde onde foi abordado como eixo temático central a valorização e a preservação do meio ambiente e ambientes favoráveis, colocando-os como fator essencial na promoção da saúde visto que, desde os anos 90 o meio ambiente e a saúde já eram reconhecidos como fatores interdependentes e inseparáveis. Duas ameaças foram citadas no evento em Sundsvall; a primeira foi atribuída ao rápido crescimento populacional e a segunda está ligada a alta migração das áreas rurais para urbanas, afetando a qualidade ou a execução dos cuidados básicos com a saúde e contribuindo para a expansão industrial e exploração de recursos naturais (BRASIL, 2002; HEIDMANN et al., 2006).

Em março de 1998, aconteceu em Genebra na Suíça a Rede de Megapaíses para a promoção da saúde; evento que ocorreu para buscar a promoção da saúde através do potencial que os países participantes tinham na ocasião. Os países participantes eram os mais populosos do mundo e juntos representavam $60 \%$ da população do mundial sendo eles: Bangladesh, Brasil, China, Índia, Indonésia, Japão, México, Nigéria, Paquistão, Federação Russa e Estados Unidos da América.

Nessa conferência foram discutidos diversos eixos temáticos na promoção de saúde retornando como pauta o meio ambiente, mas não de forma isolada como em Sundsvall, nesse momento foi associado a fonte/agravante de doenças não transmissíveis, questão também abordada sob a ótica dos custos em saúde (BRASIL, 2002).

As mudanças climáticas têm sido descritas como uma das maiores ameaças ao ambiente e a saúde humana. Uma importante consequência disso é o rápido aumento da temperatura global (REAY et al., 2007). Alguns autores têm estimado que por volta do ano de 2100 a temperatura ambiente média terá um aumento entre $1.8^{\circ} \mathrm{C}$ a $4.0^{\circ} \mathrm{C}$. Os riscos para a saúde da população estarão 
vinculados a tal mudança de temperatura, incluindo o aumento da morbidade e mortalidade devido a surtos de doenças infecciosas e exposições ao ar poluído (BACCINI et al., 2008; REAY et al., 2007).

A preocupação com as mudanças climáticas está aumentando a cada ano e tem instigado a comunidade científica a intensificar os estudos para fornecer informações e auxiliar no desenvolvimento de ações, estratégias e/ou intervenções de políticas públicas. Apesar de esse ser um conceito recente e pouco divulgado pelos meios de comunicação social, as alterações climáticas são consideradas um fenômeno natural e cíclico; porém, esse processo tem sido potencializado por alguns fatores ligados ao crescimento demográfico, avanço tecnológico e desenvolvimento científico (COELHO et al., 2004). O secretário geral da Organização das Nações Unidas (ONU), Ban ki-Moon ressaltou o tema em seu discurso na convenção das nações unidas sobre mudanças climáticas, em Copenhagen - COP 15; indicando que o clima sempre passou por alterações, mas nunca em velocidade tamanha como vem acontecendo. Ban KiMoon também ressaltou a grande influência do crescimento demográfico acelerado, econômico e industrial e como essas alterações poderão causar mudança climática global irreversível (COELHO et al., 2004; CORTESE, 2013).

As mudanças climáticas compreendem a identificação das influências mútuas da relação entre a natureza, sociedade, cultura, educação e ciência; sendo necessária qualquer intervenção que seja para mitigar ou adaptar essas mudanças. Tal compreensão envolve uma complexidade ambiental, sociocultural, educacional e a dimensão científica (VIEGAS et al., 2014).

A diferença entre mudanças climáticas e aquecimento global são claras; pode-se compreender mudanças climáticas como um termo mais amplo que refere-se ao aumento ou redução para os padrões climáticos de longo prazo, enquanto aquecimento global refere-se ao aumento da temperatura média da Terra causada por gases de efeito estufa se acumulam no ambiente (SANTOS et al., 2016).

No Brasil, a trajetória da implantação de políticas de promoção de saúde foi muito conflituosa estendendo-se por oito anos desde sua entrada em pauta no campo das políticas públicas em 1974. Os confrontos históricos que dizem respeito a entrada desse tema nas políticas públicas de saúde se deram a partir do momento que observaram tendências neoliberais de responsabilizar e/ou culpabilizar as pessoas pela própria condição de saúde, havendo uma tentativa de isentar o Estado de parte de suas funções. Como dito anteriormente, esse debate durou oito anos e passou por duas gestões do governo federal. Apesar de estar prescrito e garantido no princípio constitucional da integralidade, a promoção da saúde participa efetivamente da agenda do Ministério da Saúde a partir do ano de 1998, período onde o país era gerido ministerialmente pelo Partido da Social Democracia Brasileira (PSDB); através do projeto intitulado "Promoção da Saúde: Um Novo Modelo de Atenção"; apoiado e sustentado pelo Programa das Nações Unidas para o Desenvolvimento (PNUD), porém, 
considera-se responsável por todas as ações o Ministério da Saúde (FERREIRA NETO et al., 2013).

A partir do ano de 2003, após o início da nova gestão pública esse debate se intensificou, com a clara intenção de construir uma política nacional em bases diversas; um pouco diferente do que vinha sendo praticado pela gestão anterior. Apesar disso, somente no ano de 2006 após um longo período de debate intenso a PNPS conseguiu ser estabelecida (FERREIRA NETO et al., 2013).

A política nacional de promoção de saúde teve sua aprovação mediante a portaria ministerial no dia 30 de março de 2006 pelo ministro em exercício na época. Esse documento expõe que a maioria das políticas de saúde tinha seu foco voltado para o interior do setor público. Mesmo com a participação de um representante da Agência Nacional de Saúde Suplementar (ANS), a política nacional de promoção de saúde atuava nos níveis federal, estadual e municipal, também em algumas ações que atingiram setores não governamentais.

Nas últimas quatro décadas o Brasil vem acompanhando as tendências de mudança mundial; essas mudanças envolvem o perfil sócio demográfico, de morbimortalidade, relação saúde/doença e 0 avanço do perfil etário da população. Essas mudanças que ocorreram nos últimos 40 anos implicaram um desafio ao Sistema Único de Saúde (SUS). No Brasil, a mudança do perfil etário da população, a diminuição da taxa de fertilidade e mortalidade e as mudanças epidemiológicas caracterizadas pela mudança no padrão de adoecimento e mortalidade, estão diretamente ligadas ao desafio oferecido ao SUS e são considerados fenômenos interligados (MALTA et al., 2009).

O perfil apresentado pelos serviços de saúde no Brasil é tradicionalmente focado na intervenção de ações biomédicas individuais e curativas. No entanto, esse método intervencional é pouco eficaz, levando em consideração as mudanças demográficas sofridas nos últimos tempos e o aumento de notificações de mortalidade e morbidade por doenças crônicas não transmissíveis. A rivalidade entre a atenção clínica e a promoção de saúde não propõe melhoria na qualidade de vida da população muito menos oferece resolubilidade das ações em curso no Brasil. Nos últimos 20 anos a vivência mais intensa dos gestores e trabalhadores do SUS trouxe a tona a compreensão dos principais determinantes para a condução mais eficaz das necessidades de saúde da comunidade e a promoção de saúde passou a ter mais recursos para gerenciar os desafios ligados ao processo saúde/adoecimento. Portanto, esse momento foi muito importante para reforçar a visão e o pensamento de reduzir a vulnerabilidade da saúde pública e estimular o estilo de vida mais saudável; fazendo com que o SUS se tronasse mais organizado e capaz de criar estratégias para recompor e/ou buscar equidade e ampliação do grau de autonomia dos sujeitos e da comunidade (MALTA et al., 2009).

Seguindo essa filosofia de trabalho e pensamentos, a PNPS representa um instrumento capaz de fortalecer e implantar ações em eixos temáticos transversais com o objetivo de interligar diversos departamentos ligados à saúde 
sendo eles governamentais, não governamentais, setor privado e a sociedade, para que promovam diálogos e acompanhem uma rede de compromisso e coresponsabilidade sobre a qualidade de vida (FERREIRA NETO et al., 2013; MALTA et al., 2009).

A PNPS ao reconhecer a relevância epidemiológica do sedentarismo passa a incentivar as atividades físicas e práticas corporais. Esse reconhecimento da PNPS foi devido a participação da VIGITEL, que forneceu informações de vigilância, fatores de risco e proteção para doenças crônicas não transmissíveis através de inquérito telefônico. Nesse período a VIGITEL forneceu algumas informações importantes como: O nível de indivíduos sedentários, que representavam $29,2 \%$ dos adultos e a população fisicamente ativa representava 14,9\% no mesmo conjunto populacional observado (BRASIL, 2015).

Essa metodologia integrativa entre os diversos departamentos governamentais, organizações não governamentais (ONGs) e sociedade se mostrou eficaz e fundamental para a promoção da saúde. Assim observando; as parcerias entre os setores da administração pública (Educação, Meio Ambiente, Agricultura, Trabalho, Indústria e Comércio, Transporte, Direitos Humanos e outros), foi capaz de atuar nas mudanças sociais, econômicas e ambientais que foram benéficas para as políticas públicas, garantindo os direitos de cidadania e a autonomia dos sujeitos e coletividades (BRASIL, 2015; MALTA et al., 2016)

A importância do tema no curso de Educação Física, pode ser vista quando são evidenciadas a maneira que o ambiente exerce suas influências sobre o organismo, na disciplina de Fisiologia do Exercício, Fisiologia Humana, Primeiros Socorros no Esporte, Avaliação, prevenção e tratamento imediato das lesões esportivas (MCARDLE; KATCH; KATCH, 2011) (HILLMAN, 2002), (FLEGEL, 2002), (GUYTON; HALL; GUYTON, 2006), são abordados os seguintes tópicos:

- Equilíbrio térmico

- Termorregulação no estresse ao frio: conservação e produção de calor

- Termorregulação no estresse pelo calor: perda de calor

- Perda de calor por evaporação nas temperaturas ambientais elevadas

- Perda de calor numa umidade elevada

- Perda de água no calor: desidratação

- Complicações do estresse térmico excessivo

- Complicações respiratórias durante o exercício em baixas temperaturas

- Taxa em que o ar alveolar é renovado pelo ar atmosférico

- Concentração e pressão parcial dos diversos gases atmosféricos

- Efeito da razão ventilação/perfusão na concentração de gás alveolar

- Hipoxia e Hipercapnia

- Problemas relacionados ao clima

- Hipotermia e Hipertermia

- Intermação

- Doenças emergências respiratórias

- Regulação da temperatura e troca de calor 
- Respostas fisiológicas ao exercício no calor

- Mecanismos de resfriamento

- Adaptando-se ao calor ambiental

- Doenças causadas pelo calor

- Prevenção de doenças relacionadas ao calor

- Tratamento de doenças causadas pelo calor

- Meio ambientes frios

O exercício físico sendo caracterizado como uma atividade planejada, programada; com objetivos bem definidos e praticado de maneira regular é considerado uma grande ferramenta na promoção de saúde e prevenção de doenças crônicas não transmissíveis, atuando de maneira direta na redução de diversas enfermidades como: hipertensão, infarto agudo do miocárdio, diabetes, depressão e outras (LEE et al., 2012). O aumento e a adesão populacional a programas de exercício físico é essencial na promoção da saúde e no enfrentamento de doenças, essa questão é de tamanha relevância que a Organização Mundial da Saúde (OMS) definiu como meta que os países tentem reduzir em $10 \%$ os níveis de inatividade física da população (MALTA et al., 2015).

Existe um consenso global sobre as recomendações para a prática de exercício físico, esse consenso acontece pelas duas instituições responsáveis pelas recomendações e guideline em ciências do esporte que são: American College of Sport Medicine (ACMS) e o European College of Sport Science (ECSS). As instituições recomendam que adultos devam praticar semanalmente pelo menos 150 minutos de exercício físico de caráter leve ou moderado ou 75 minutos de exercício físico de caráter intenso. Essas recomendações são diretrizes referentes a valores mínimos, que devem ser praticados para obter adaptações orgânicas positivas, contribuindo na promoção de saúde e prevenção de patologias crônicas não transmissíveis (MALTA et al., 2015).

As mudanças climáticas podem oferecer riscos à saúde humana sob três aspectos. O primeiro aspecto a ser observado é referente às mudanças ou variações climáticas consideradas extremas, considerando que podem afetar diretamente a saúde devido a sua ação direta na fisiologia; como por exemplo, o aumento na frequência ou intensidade das ondas de calor, que podem contribuir para o aumento da mortalidade. $O$ segundo aspecto refere-se às mudanças no meio ambiente que interferem diretamente na saúde, por exemplo, as mudanças climáticas e a produção agrícola e recursos hídricos, variações que podem representar um desequilíbrio e gerar escassez de alimentos e água. E o terceiro às alterações de processos sociais, como migração de grupos populacionais do meio rural para o urbano, o que causaria o agravamento de problemas sociais ligados à carência ou deficiência da infraestrutura urbana (SOUZA et al., 2013). Portanto, a variação climática interfere diretamente sobre a resposta do organismo durante a prática de atividades físicas.

Durante o exercício físico a estimulação muscular e super ativação metabólica produzem o aumento da temperatura interna, gerando energia e 
liberando calor; esse calor produzido internamente precisa ser transferido para o meio externo para que não ocorra superaquecimento. Um ambiente em condições quentes e/ou úmido pode agravar o esforço do organismo durante o exercício físico, aumentando a temperatura corporal. A sudorese é um importante recurso no processo de termo regulação, porém, nem sempre é suficiente para manter a homeostase da temperatura durante o esforço físico para evitar o calor e a insolação. Os fatores climáticos como vento e umidade influenciam diretamente os efeitos do calor na temperatura corporal durante momentos ativos e de descanso (STAMATAKIS et al., 2013). Fisiologicamente, em dias mais quentes o processo homeostático de termorregulação impõe sobrecarga de trabalho ao sistema cardiovascular e respiratório induzindo o aumento da viscosidade sanguínea pela desidratação e colesterol na corrente sanguínea. Já em temperaturas mais frias, o sistema cardiovascular sofre um estresse adicional em virtude da adaptação pressórica gerada pela maior contratilidade vascular (vasoconstrição), aumento da quantidade de hemácias e hemoglobinas, colesterol e fibrinogênio plasmático. Associado a isso, o frio induz o sistema respiratório a sofrer broncoconstrição, aumentando a suscetibilidade as doenças pulmonares obstrutivas crônicas (DPOC) (CASAS, 2015; KENNEY; CRAIGHEAD; ALEXANDER, 2014; SOUZA et al., 2013).

Nos últimos anos o tema de alterações climáticas veio crescendo e ganhando cada vez mais espaço. Quando se fala em alterações climáticas e fatores que implicam negativamente na saúde humana surge também a preocupação de como o organismo reage exercendo esforço em condições climáticas desfavoráveis. $O$ interesse por esse tema aumentou após relatos de episódios que envolvem condições climáticas extremas e a influência que isso tem na saúde humana. Mesmo havendo consenso entre os pesquisadores da área sobre a ocorrência das temperaturas extremas frias e temperaturas extremas quentes, e como afetam a saúde, sua importância é assunto de debate e investigações principalmente em detalhes cuja associação do tema ainda não foi explorada (GASPARRINI et al., 2015).

As variações de temperatura associadas às variações da umidade relativa do ar são descritas como responsáveis diretos por comprometimento do sistema respiratório e cardiovascular durante o esforço físico. Sendo assim, tanto a poluição que interfere a qualidade do ar atmosférico quanto às alterações climáticas, associadas ou não, podem comprometer a saúde humana, principalmente de populações mais susceptíveis como idosos e crianças (CHRISTIANE et al., 2016). Em 1998, em uma de suas obras cientificas; Garcia listou os principais riscos e sintomas causados pela ação das condições climáticas desfavoráveis sobre o organismo humano. Sobre os riscos, os principais destacados em sua obra foram os problemas cardiovasculares, respiratórios e fatores ligados ao aumento da temperatura e umidade relativa do ar que induz a hipertermia durante o exercício; os sintomas que se destacam são: sede excessiva; perda de apetite; náusea ou vômito; inquietude; comportamento irracional e confusão; pupilas dilatadas; fadiga; sudorese 
excessiva ou ausência de sudorese; fraqueza; urina concentrada; pele pálida e pegajosa. Quando esses sintomas permanecem devido as condições de temperatura e umidade, a situação pode progredir para um choque hipertérmico, causando: pele seca e quente; câimbras musculares; vermelhidão; respiração superficial e rápida; pulsação rápida e fina; convulsões e inconsciência (GARCIA; RODRIGUES, 1998).

Por essas razões acima apresentadas, o profissional de Educação Física necessita de um aprimoramento técnico na questão climática relacionada à saúde, pois os profissionais têm estimulado cada vez mais a participação dos indivíduos em programas de treinamentos em ambientes abertos e expostos diretamente as condições climáticas como recurso na melhora da qualidade de vida (CHRISTIANE et al., 2016). Contudo, a pesquisa busca identificar o conhecimento de acadêmicos do curso de Educação Física (licenciatura e bacharelado) a respeito das alterações climáticas e a importância do tema na formação acadêmica e atuação profissional.

\section{Materiais e métodos}

\section{Características do estudo e recrutamento de participantes}

Trata-se de um estudo quantitativo descritivo, realizado em uma universidade do interior de São Paulo. A pesquisa caracteriza-se por se tratar de uma forma de coleta de dados online, porém, parte do processo de divulgação / recrutamento ocorreu de forma presencial. O contato inicial com os possíveis participantes aconteceu de forma presencial em suas salas de aula. Nessa etapa foi feito um convite aos alunos a participarem da pesquisa e, explicar e expor as informações necessárias, ensinado como encontrar o questionário na plataforma do aluno (Blackboard); foi informado que no próprio link de acesso ao questionário havia acesso ao TCLE e posteriormente, as questões da pesquisa, Além de tirar algumas dúvidas dos alunos. Essa etapa teve uma duração média de 10 minutos por sala.

\section{Espaço amostral e características da amostra}

Aproximadamente 600 alunos de graduação do curso de Educação Física foram convidados a participar da pesquisa, preencheram um Termo de Consentimento Livre e Esclarecido (TCLE) e o questionário específico; ambos inseridos na plataforma Blackboard no portal do aluno. Esse questionário foi disponibilizado para os alunos do curso de Educação Física do $1^{\circ}$ ao $8^{\circ}$ período (Licenciatura e Bacharelado) das turmas diurnas e noturnas. O questionário esteve disponível para acesso a partir da data de divulgação do estudo, do dia 8/9/2016 até 11/11/2016. Foi utilizado como critério de inclusão: ser aluno de graduação em Educação Física e, estar regularmente matriculado na Instituição de Ensino Superior (IES). 
A amostra foi composta de 100 alunos dos cursos de Educação Física (Licenciatura e Bacharelado), de ambos os sexos, com variação de idade de 17 a 49 anos.

\section{Questionário}

Foi aplicado um questionário online composto por 35 questões, sendo dividido em questões dissertativas e de múltipla escolha na temática de mudanças climáticas e saúde. Estas questões objetivam a caracterização e compreensão dos estudantes para a percepção, crenças, motivação, preocupação, atitudes e conhecimento relacionado ao tópico das alterações climáticas. O questionário foi adaptado de Santos et al. (2016) e desenvolvido com uma linguagem acessível para facilitar o entendimento e a adesão dos participantes.

\section{Aspectos éticos}

A presente pesquisa obteve parecer favorável e aprovação dos requisitos éticos do Comitê de Etica em Pesquisa (CEP), da Universidade de Franca UNIFRAN; atendendo todas as recomendações e diretrizes com pesquisas em seres humanos e utilização de questionários, seguindo os princípios estabelecidos pelo (Conselho Nacional de Saúde, Resolução 466/12). A pesquisa foi aprovada com o parecer de número 1.563.966.

\section{Tratamento estatístico}

Após o término do período de acesso e respostas do questionário os dados foram obtidos através de um arquivo de Excel, onde, posteriormente foi feito uma organização dos dados e remoção dos códigos gerados pela plataforma de acesso do questionário. Para avaliar a relação entre faixa etária, sexo e as demais variáveis qualitativas de interesse foi utilizado o teste exato de Fisher ao nível nominal de 5\% de significância. Este teste é preferível ao Quiquadrado quando as células da tabela de contingência possuem frequências observadas menores do que 5 .

Todas as análises foram realizadas no software $R$ (RDEVELOPMENT, 2013).

\section{Resultados}

A pesquisa foi divulgada para o curso de Educação Física (Licenciatura e Bacharelado) de uma universidade do interior paulista. $O$ espaço amostral representado pelos alunos cuja divulgação foi feita, chegou ao número de 720 . Este total pode ser desmembrado em duas categorias do curso, sendo a categoria Bacharelado, que corresponde a um total de 321 alunos e de Licenciatura com uma quantidade de 399. Contudo, a quantidade de alunos que acessaram a plataforma e entraram no arquivo do questionário foi de 425 , 
representando $59 \%$ do número total da divulgação. Após a análise do número de acesso partiu-se para a quantificação do número de alunos que responderam o questionário. Nessa etapa, foi observado um número de 211, porém, o número correspondente de alunos que tiveram sua avaliação validada foi de 102. Desses 102, pode-se utilizar os questionários para análise de 100 uma vez que dois alunos discordaram dos termos do TCLE (Termo de Consentimento Livre e Esclarecido). Ao analisarmos o tamanho da amostra válida, com o número total de divulgação, chega-se a um número representativo em percentil do $\mathrm{N}$ da pesquisa de $13,88 \%$.

Sob o aspecto da caracterização da amostra pode-se apontar que foi composta por 100 participantes. Após a análise do domínio gênero, foi constatado certo equilíbrio entre masculino e feminino, representando 54 (54\%) e $46(46 \%)$, respectivamente. A idade dos participantes variou de 17 a 49 anos de idade, sendo a idade média de 23,07 anos.

Quando perguntados sobre a crença de que as alterações climáticas estejam acontecendo nesse momento, $81,92 \%$ dos avaliados responderam que acreditam, enquanto 1,06\% disseram não estar acontecendo; o restante apontou como talvez ou não souberam opinar, representando valores de 13,83\% e 3,19\% respectivamente. Sobre o aspecto de interesse, preocupação e nível importância dos estudantes sobre o tópico de alterações climáticas é encontrado um dado interessante sob a ótica da homogeneidade das observações, através da divisão de gêneros. Quando avaliados de forma geral no contexto de interesse do tema das alterações climáticas, nota-se um equilíbrio entre as respostas, onde apontam como muito interessante $(49,50 \%)$ e pouco interessante $(50,50 \%)$. Nessa mesma questão, quando observada através da divisão de gênero, podese concluir que os homens demonstraram mais interesse no tema em relação às mulheres. Cerca de $54,72 \%$ dos homens apontaram como tema de muito interesse, contra $43,48 \%$ das mulheres. Ainda na mesma questão, se analisado o nível de interesse de acordo com a idade apresentada pelos avaliados, percebe-se que os avaliados que possuem de 17 a 20, e 41 a 50 anos de idade se mostram pouco interessados ao tema com um valor correspondente a $(61,7 \%)$ e $(0 \%)$, respectivamente. Já nas faixas etárias de 21 a 30 e 31 a 40 anos de idade esses grupos se mostraram muito interessados ao tema, apresentando $(55,2 \%)$ e $(83,3 \%)$, respectivamente.

Quando questionados sobre a importância do tema das alterações climáticas, $73,32 \%$ dos avaliados consideram o assunto de muita ou bastante importância. Essa questão se mostrou sólida quando comparamos entre os gêneros, onde os dados apontam que $80,43 \%$ das mulheres e $74,51 \%$ dos homens mostraram que as alterações climáticas fazem parte de um contexto de grande importância. No entanto, a questão da importância do tema fica ainda mais evidente quando comparamos as respostas de acordo com as faixas etárias. Percebe-se pelos resultados que todas as faixas etárias demonstraram um alto nível de interesse no tema. Os dados apontam como de muita importância nas faixas etárias de 17 a 20 anos de idade, 21 a 30 anos, 31 a 40 e 
41 a 50 anos os seguintes valores, (81,8\%), (72,4\%), (100\%) e (100\%), respectivamente.

Assim como na avaliação de importância, a avaliação de preocupação se manteve bem semelhante. Porém com uma leve redução nas faixas etárias de 17 a 20 anos de idade, passando de $81,8 \%$ para $78,8 \%$ e um sutil aumento na faixa etária de 21 a 30 anos de idade, que na importância apontou como 72,4\% e na preocupação passou para $75,8 \%$. Já as duas últimas faixas etárias, de 31 a 40 e de 41 a 50 anos se mantiveram em 100\%. Em linhas gerais, pode-se dizer que os valores foram praticamente iguais nas avaliações de importância e preocupação, onde se mostraram muito importante e muito preocupado, $(77,3 \%)$ e $(78,3 \%)$, respectivamente.

Ao mesmo tempo a percepção dos impactos das alterações climáticas foi avaliada tanto nas comunidades humanas, comunidades biológicas, no Brasil ou no exterior. Essa percepção foi avaliada sob a forma de escalas de tempo para cada uma das questões. Essa escala consiste na percepção de já haver impactos visíveis; em haver impactos em 10 anos; em 25 anos; em 50 anos; em 100 anos; ou nunca. Foi então perguntado sobre a percepção dos impactos nas comunidades humanas do Brasil e dos países do exterior. Essa questão mostrou certa semelhança no perfil de percepção dos avaliados onde 70,22\% apontaram que já é possível observar impactos das alterações climáticas nas comunidades humanas no Brasil, e $69,16 \%$ mostraram que também é possível notar as mudanças nas comunidades humanas no exterior. Cerca de $10 \%$ apontaram que os impactos no Brasil seriam notados daqui a 10 anos contados a partir da resposta do questionário, e cerca de $13 \%$ disseram que seria percebido no mesmo período de tempo no exterior, $9 \%$ apontaram que seria os impactos surgiriam em 25 anos, tanto no Brasil quanto no exterior, 3\% dos avaliados disseram que os impactos surgiriam em 50 anos tanto no Brasil quanto no exterior, $2 \%$ apontaram que os impactos seriam observados daqui a 100 anos no Brasil e 3\% no exterior, e 1\% disseram que nunca haveria impactos tanto no Brasil quanto no exterior. Quando analisada essa mesma questão com diferenciação de gênero, percebe-se que $72,2 \%$ mulheres apontam já perceber os impactos nas comunidades humanas no Brasil, contra $68 \%$ dos homens. Ao serrem perguntados sobre os impactos das comunidades humanas em outros países, os homens aparecem com maior porcentagem, $77 \%$, contra $60 \%$ das mulheres. Quando se trata dos impactos daqui a 10 anos as mulheres sobressaem tanto no Brasil quanto em outros países, (15,91\%) e $(26,67 \%)$, contra $(6 \%)$ e $(2,4 \%)$ dos homens, respectivamente.

Quando perguntados sobre os impactos nas comunidades biológicas tanto do Brasil quanto de outros países, percebe-se certa semelhança com os resultados da pergunta anterior, porém as mulheres acreditam mais nos impactos sofridos pelas comunidades biológicas do que os impactos sofridos pela comunidade humana, seja no Brasil ou em outros países. Enquanto $72,74 \%$ das mulheres acreditam já haver os impactos na comunidade humana no Brasil, $76,08 \%$ das mulheres acreditam que os impactos já acontecem nas 
comunidades biológicas por aqui. Quando comparado somente entre outros países esse número fica ainda mais acentuado, pois $79,56 \%$ das mulheres acreditam que já há impactos nas comunidades biológicas em outros países, no entanto $60 \%$ das mulheres acreditam que haja impacto na comunidade humana de outros países. No caso dos homens, ao comparar as comunidades biológicas e humana no Brasil, eles acreditam que haja mais impacto nas comunidades biológicas, apresentando valores de $72 \%$ contra $68 \%$, respectivamente. Em outros países, os homens acreditam que os impactos na comunidade humana permanecem o mesmo que o Brasil, apresentando $68 \%$, porém, quando se referem a comunidade biológica de outros países, $77,56 \%$ acreditam já ter impactos.

No contexto geral, os avaliados dizem já perceber os impactos das alterações climáticas sobre as comunidades biológicas no Brasil e em outros países em $(73 \%)$ e $(75 \%)$, respectivamente. Quando comparados pelas faixas etárias é possível perceber certa homogeneidade no perfil das respostas, não apresentando grandes diferenças entre as categorias etárias.

Todos os resultados estão apresentados nas Tabelas 1 e 2.

Tabela 1: Percepção dos entrevistados em função da faixa etária.

\begin{tabular}{|c|c|c|c|c|c|c|c|}
\hline \multirow{7}{*}{$\begin{array}{c}\text { O tópico } \\
\text { mudanças } \\
\text { climáticas } \\
\text { tem... }\end{array}$} & & & $\begin{array}{c}17-20 \text { anos } \\
n(\%)\end{array}$ & $\begin{array}{c}21-30 \text { anos } \\
n(\%)\end{array}$ & $\begin{array}{c}31-40 \text { anos } \\
n(\%)\end{array}$ & $\begin{array}{c}41-50 \text { anos } \\
n(\%)\end{array}$ & Total n $(\%)$ \\
\hline & \multirow{2}{*}{ Interesse } & Muito & $13(38,3)$ & $32(55,2)$ & $5(83,3)$ & $Q(0,0)$ & $50(50,5)$ \\
\hline & & Pouco & $21(61,7)$ & $26(44,8)$ & $1(16,7)$ & $1(100)$ & $49(49,5)$ \\
\hline & \multirow{2}{*}{ Importância } & Muito & $27(81,8)$ & $42(72,4)$ & $5(100)$ & $1(100)$ & $75(77,3)$ \\
\hline & & Pouco & $6(18,2)$ & $16(27,6)$ & $Q(0,0)$ & $Q(0,0)$ & $22(22,7)$ \\
\hline & \multirow{2}{*}{ Preocupação } & Muito & $26(78,8)$ & $44(75,8)$ & $5(100)$ & $1(100)$ & $76(78,3)$ \\
\hline & & $\begin{array}{l}\text { Pouco } \\
\text { Já há }\end{array}$ & $\begin{array}{c}7(21,2) \\
23(71,8)\end{array}$ & $\begin{array}{l}14(24,2) \\
43(74,1)\end{array}$ & $\begin{array}{l}Q(0,0) \\
4(80,0)\end{array}$ & $\begin{array}{l}Q(0,0) \\
1(100)\end{array}$ & $\begin{array}{l}21(21,7) \\
71(73,9)\end{array}$ \\
\hline \multirow{23}{*}{$\begin{array}{c}\text { Percepção } \\
\text { dos impactos } \\
\text { das } \\
\text { mudanças } \\
\text { climáticas... }\end{array}$} & nas & $\mathrm{Em} 10$ anos & $4(12,5)$ & $3(5,2)$ & $Q(0,0)$ & $Q(0,0)$ & $7(7,3)$ \\
\hline & comunidades & Em 25 anos & $4(12,5)$ & $4(6,9)$ & $Q(0,0)$ & $0(0,0)$ & $8(8,3)$ \\
\hline & biológicas no & Em 50 anos & $1(3,2)$ & $3(5,2)$ & $1(20,0)$ & $Q(0,0)$ & $5(5,3)$ \\
\hline & \multirow[t]{3}{*}{ Brasil } & $\mathrm{Em} 100$ anos & $Q(0,0)$ & $3(5,2)$ & $Q(0,0)$ & $Q(0,0)$ & $3(3,2)$ \\
\hline & & Nunca haverá & $Q(0,0)$ & $2(3,4)$ & $Q(0,0)$ & $Q(0,0)$ & $2(2,0)$ \\
\hline & & Já há & $23(74,2)$ & $40(70,2)$ & $3(60,0)$ & $Q(0,0)$ & $66(70,2)$ \\
\hline & nas & Em 10 anos & $3(9,7)$ & $7(12,3)$ & $Q(0)$ & $1(100)$ & $11(11,7)$ \\
\hline & comunidades & $\operatorname{Em} 25$ anos & $4(12,9)$ & $4(7,0)$ & $1(20,0)$ & $Q(0,0)$ & $9(9,6)$ \\
\hline & humanas no & $\mathrm{Em} 50$ anos & $Q(0,0)$ & $3(5,2)$ & $1(20,0)$ & $Q(0,0)$ & $4(4,3)$ \\
\hline & \multirow[t]{3}{*}{ Brasil } & $\mathrm{Em} 100$ anos & $Q(0,0)$ & $2(3,6)$ & $Q(0,0)$ & $Q(0,0)$ & $2(2,1)$ \\
\hline & & Nunca haverá & $1(3,2)$ & $1(1,7)$ & $Q(0,0)$ & $Q(0,0)$ & $2(2,1)$ \\
\hline & & Já há & $25(80,6)$ & $43(75,6)$ & $4(80,0)$ & $Q(0,0)$ & $72(76,7)$ \\
\hline & \multirow{6}{*}{$\begin{array}{c}\text { nas } \\
\text { comunidades } \\
\text { biológicas em } \\
\text { outros paises }\end{array}$} & $\mathrm{Em} 10$ anos & $2(6,5)$ & $5(8,8)$ & $Q(0,0)$ & $Q(0,0)$ & $7(7,4)$ \\
\hline & & $\operatorname{Em} 25$ anos & $2(6,5)$ & $3(5,2)$ & $Q(0,0)$ & $1(100)$ & $6(6,4)$ \\
\hline & & Em 50 anos & $1(3,2)$ & $3(5,2)$ & $1(20,0)$ & $Q(0,0)$ & $5(5,3)$ \\
\hline & & $\mathrm{Em} 100$ anos & $1(3,2)$ & $3(5,2)$ & $Q(0,0)$ & $Q(0,0)$ & $4(4,2)$ \\
\hline & & Nunca haverá & $Q(0,0)$ & $Q(0,0)$ & $Q(0,0)$ & $Q(0,0)$ & $Q(0)$ \\
\hline & & Já há & $23(74,2)$ & $40(71,5)$ & $2(33,3)$ & $Q(0,0)$ & $65(69,1)$ \\
\hline & \multirow{5}{*}{$\begin{array}{c}\text { nas } \\
\text { comunidades } \\
\text { humanas em } \\
\text { outros paises }\end{array}$} & $\mathrm{Em} 10$ anos & $4(12,9)$ & $7(12,5)$ & $2(33,3)$ & $1(100)$ & $14(14,9)$ \\
\hline & & $\operatorname{Em} 25$ anos & $4(12,9)$ & $3(5,3)$ & $1(16,7)$ & $Q(0,0)$ & $\&(8,5)$ \\
\hline & & Em 50 anos & $Q(0,0)$ & $2(3,6)$ & $1(16,7)$ & $Q(0,0)$ & $3(3,2)$ \\
\hline & & Em 100 anos & $Q(0,0)$ & $3(5,3)$ & $Q(0,0)$ & $Q(0,0)$ & $3(3,2)$ \\
\hline & & Nunca haverá & $Q(0,0)$ & $1(1,8)$ & $Q(0,0)$ & $Q(0,0)$ & $1(1,1)$ \\
\hline Total n (\%) & & & $35(35,0)$ & $58(58,0)$ & $6(6,0)$ & $1(1,0)$ & \\
\hline
\end{tabular}


Tabela 2: Percepção dos entrevistados em função do sexo.

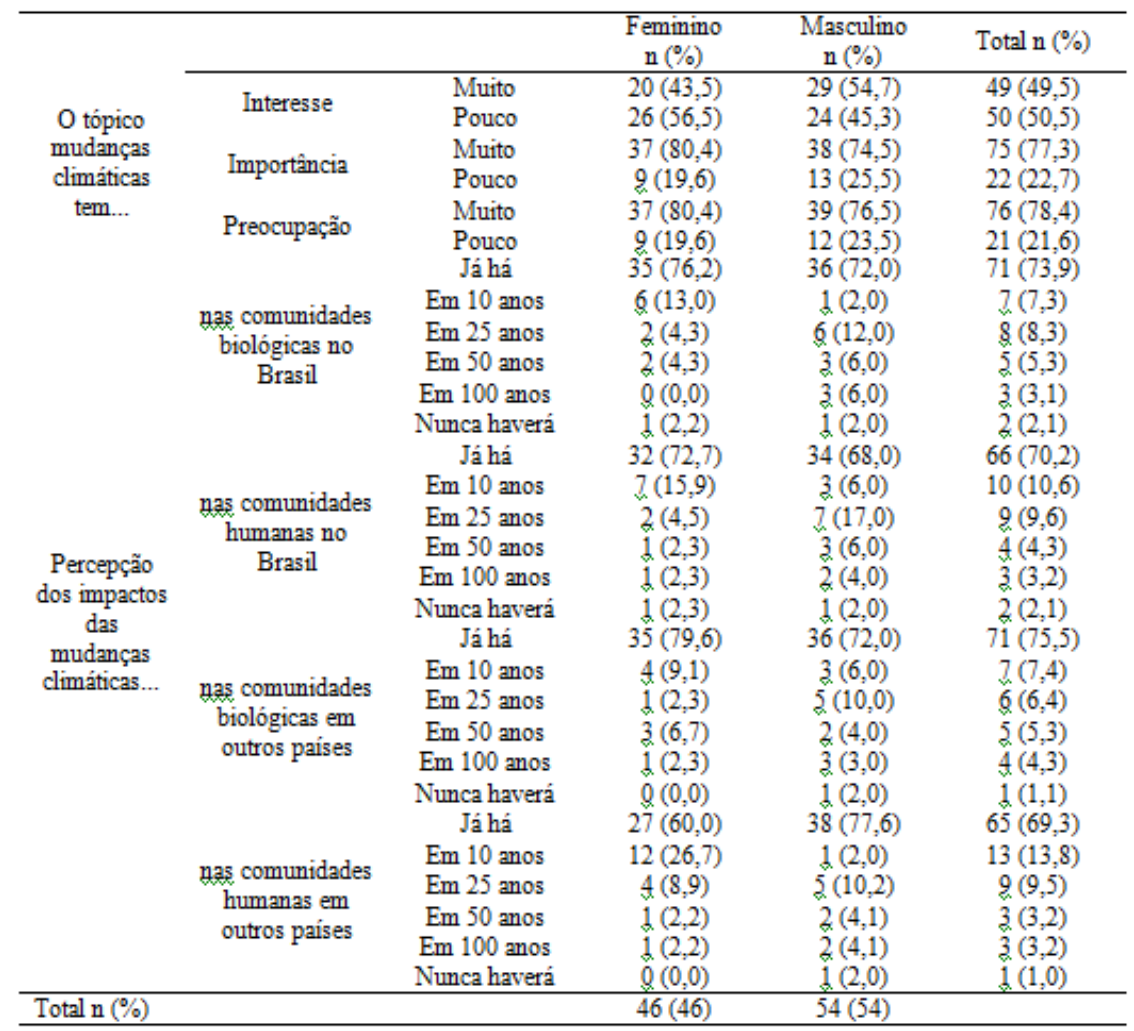

A maioria dos estudantes (94,62\%) acreditam que a ação humana é a causa mais importante nas alterações climáticas (contra 3,22\% que acreditam que a ação humana não é a responsável pelas alterações). Quando perguntados se as pessoas que as cercam possuem hábitos que mitigam as alterações climáticas; quase metade dos estudantes $(48,95 \%)$ responderam que parcialmente, enquanto $5,31 \%$ disseram que sim, e $28,72 \%$ disseram que não. Nessa questão $17,02 \%$ dos estudantes não souberam opinar. Mesmo a maioria dos estudantes expressando haver fortes influências das ações humanas sobre as alterações climáticas, quando perguntados sobre o comportamento da humanidade em relação às alterações, 39,13\% das pessoas acreditam que pode minimizar os efeitos, mas não tem certeza se fará o necessário; já 45,65\% dos estudantes acreditam que podem minimizar os efeitos das alterações climáticas, mas enfatizam que a humanidade não fará o necessário. Sobre a humanidade não ter o poder de minimizar e não acreditam nas alterações climáticas, temos $2,18 \%$ e 1,09\%, respectivamente (Figura 1). 


\section{Qual sua opinião sobre o comportamento da humanidade sobre as alterações climáticas?}

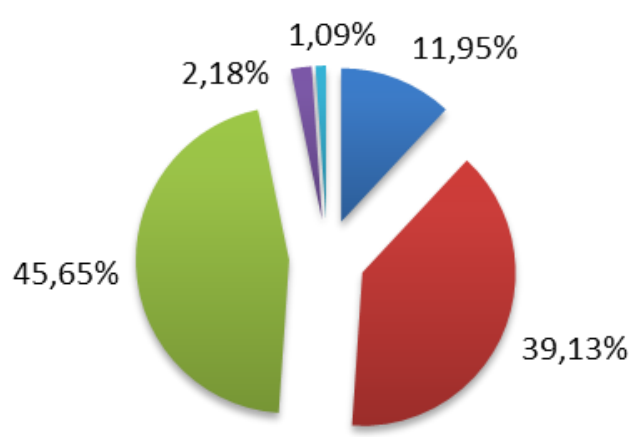

\footnotetext{
- Pode minimizar os efeitos e vai conseguir.

- Pode minimizar os efeitos, mas não tem certeza se fará o necessário.

Pode minimizar, mas as pessoas não irão alterar seus comportamentos e não irão fazer.

n Não pode minimizar.
}

Figura 1. Opinião dos entrevistados sobre o comportamento da humanidade sobre as alterações climáticas.

Houve um equilíbrio no pensamento dos estudantes, quando foram questionados de quem era o papel mais importante ou quem deveria tomar as principais ações sobre as alterações climáticas, $48,35 \%$ dos estudantes apontaram que o papel maior e o principal responsável são os governos, já $40,66 \%$ disseram que os indivíduos tem a responsabilidade de se esforçar para minimizar os efeitos, e pouco menos de $11 \%$ afirmam que essa responsabilidade cabe às empresas privadas (Figura 2).

\section{Quem devia tomar as ações principais para minimizar as alterações climáticas?}

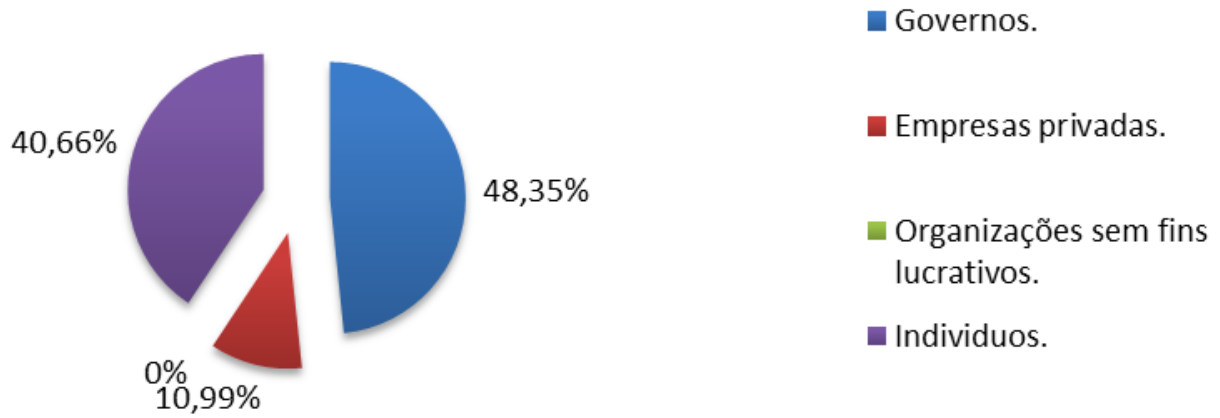

Figura 2: Opinião dos entrevistados sobre responsáveis pelas medidas de minimização das alterações climáticas.

Quando perguntados se apoiariam medidas que contribuíssem para a redução da emissão de gases do efeito estufa, mesmo que essas medidas implicassem em pagar mais pelo combustível, energia elétrica, etc.; a maioria 
das pessoas $(47,78 \%)$ se diz a favor, enquanto $21,11 \%$ das pessoas se opõem a essa saída, e $31,11 \%$ dos estudantes disseram não saber opinar sobre isso.

Quanto a auto avaliação dos estudantes sobre seu conhecimento técnico a respeito do assunto alterações climáticas, ficou evidente que os alunos se autodenominam com conhecimento mínimo e moderado, representando uma taxa de $45,05 \%$ e $50,55 \%$, respectivamente. Somente $4,40 \%$ se classificam com conhecimento extenso do tema. Sobre o conhecimento dos estudantes sobre a influência do seu comportamento sobre as alterações climáticas, a maioria dos alunos $(59,34 \%)$ se julga com conhecimento moderado, $24,18 \%$ com conhecimento mínimo e $16,48 \%$ com conhecimento extenso sobre a influência do seu comportamento sobre as alterações climáticas (Figura 3).

\section{O meu conhecimento técnico sobre as alterações climáticas é...}
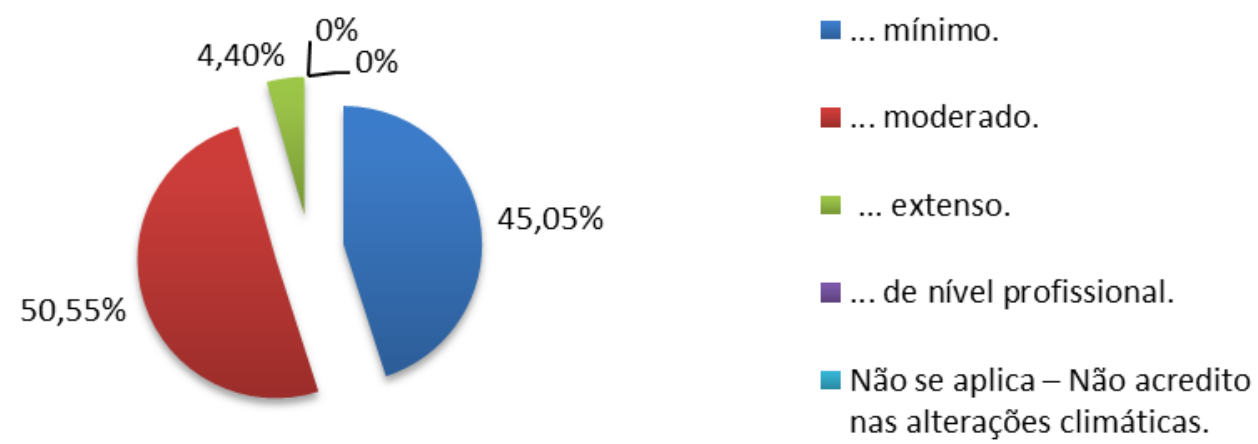

Figura 3: Opinião dos entrevistados sobre seu conhecimento pessoal das alterações climáticas.

Ao serem questionados sobre a abordagem que o curso de graduação em Educação Física (Licenciatura e Bacharelado) tem a respeito das alterações climáticas ao longo da formação, os alunos manifestaram-se de forma distribuída; porém, a maioria alega que o curso focou de forma insuficiente no tema $(37,78 \%)$. Uma parte dos avaliados disseram que o curso focou o suficiente nas alterações climáticas, o percentual desse grupo chega a 14,44\%; $24,44 \%$ das pessoas disseram não ter percebido a abordagem em nenhum momento do curso e cerca de $23,34 \%$ disseram que obtiveram as informações sobre o tema informalmente (Figura 4). 


\section{Considera que a sua formação acadêmica focou no assunto das alterações climáticas?}

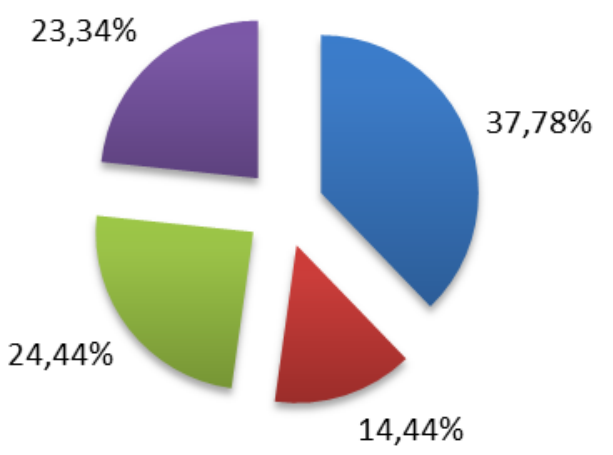

De forma insuficiente.

De forma suficiente.

Não percebi alguma vez ter focado no assunto.

não, mas obtive a informação informalmente.

Figura 4: Opinião dos entrevistados sobre sua formação acadêmica e a abordagem do tema das alterações climáticas.

Quando foi pedido para descreverem as disciplinas que abordaram o assunto de mudanças climáticas ou a influência do meio ambiente na saúde humana a resposta "não teve" e "não sei" apareceram com grande frequência, essa resposta apareceu em 32 e 7 vezes, respectivamente (Figura 5).

Figura 5: Disciplinas ou ocasiões que abordaram o tema de alterações climáticas.

Quando perguntados sobre a importância da temática das alterações climáticas na formação profissional quase metade (47,78\%) dos avaliados apontaram como muito importante, $32,22 \%$ disseram ser moderadamente importante ter o conhecimento das alterações climáticas durante a formação 
profissional, $7,78 \%$ e $12,22 \%$ apontaram não ser importante e importante somente para algumas áreas medicas, respectivamente (Figura 6).

\section{Qual a importância que a temática das alterações climáticas deverá ter na sua formação profissional?}

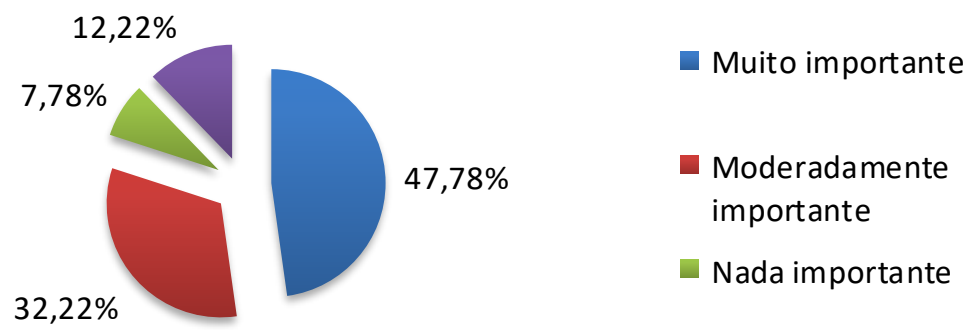

Figura 6: Opinião dos entrevistados sobre a importância da temática das alterações climáticas na sua formação profissional.

Sobre a importância do conhecimento das alterações climáticas durante a prática profissional $38,20 \%$ dos alunos apontam ser muito importante, $43,82 \%$ dizem ser moderadamente importante, $14,61 \%$ afirmam ser pouco importante e $3,37 \%$ afirmam não ser importante na pratica profissional.

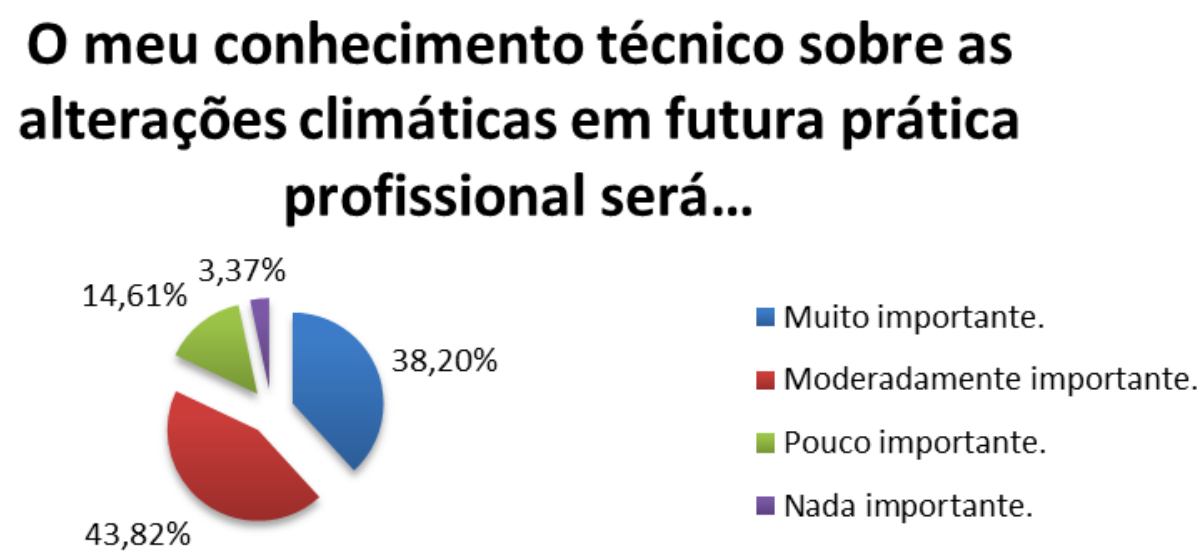

Figura 7: Opinião dos entrevistados sobre o uso do conhecimento técnico das alterações climáticas na sua prática profissional. 


\section{Discussão}

A educação, em todos os níveis, é uma ferramenta de extrema importância para o desenvolvimento técnico, científico, pessoal e profissional das pessoas. Pois, com um bom planejamento e execução das propostas educacionais os indivíduos podem desenvolver ou criar pensamentos produtivos em diversos campos, melhorando suas capacidades cognitivas ligadas a percepção do que acontece ao seu redor, melhora do senso crítico e melhora da conscientização entre o certo e o errado, de forma geral (HARKER-SCHUCH; BUGGE-HENRIKSEN, 2013). Nesse contexto a educação também atua de maneira primorosa nas capacidades de percepções e atitudes sobre o tema das alterações climáticas. As percepções das pessoas sobre as alterações climáticas não são simples e possuem um contexto com muitas dimensões a serem analisadas (SANTOS et al., 2016).

Esta pesquisa expõe os resultados coletados entre os estudantes de graduação dos cursos de Educação Física, licenciatura e bacharelado de uma universidade do interior paulista. Uma pesquisa desenvolvida com a proposta bem parecida com o trabalho desenvolvido por Santos et al., (2016), onde avaliou a percepção dos alunos do segundo ciclo das turmas de pós-graduação acerca das alterações climáticas. No entanto, o que diferencia os dois trabalhos é que, além da diferença da população de estudantes, pós-graduandos em Portugal e graduandos no Brasil, a população utilizada no estudo do Brasil é representativa ao curso de graduação, fato que não ocorreu na pesquisa portuguesa.

Para reforçar a necessidade da abordagem do tema no contexto educacional e o interesse do governo federal brasileiro, busca-se promover medidas que qualifique e gere maior envolvimento do sistema educacional com o tema das alterações climáticas, propondo e organizando conferências e produção de materiais didáticos. Essas medidas servem para estimular o aprendizado social ligados ao processo de reflexão crítica sobre a necessidade de mudanças de práticas e atitudes individuais e sociais (JACOBI et al., 2011). Porém, essas medidas parecem não estarem sendo aplicadas em todos os níveis educacionais, como por exemplo, no ensino superior.

$\mathrm{Na}$ presente pesquisa grande parte dos universitários acredita que as alterações climáticas estão acontecendo nesse momento, acreditam também que essas mudanças no clima possuem grande interferência das atividades humanas e dizem precisar de mais informações sobre esse tema. Fato confirmado quando perguntados sobre questões específicas das alterações climáticas, onde suas respostas correspondem bem seu conhecimento e auto percepção. Diferentemente desse resultado, a pesquisa de Santos et al., (2016), onde a auto percepção dos alunos não se mostrou condizente com as respostas de perguntas específicas do tema proposto.

Não foi o caso do resultado entre os graduandos, mas a propagação de crenças errôneas de qualquer natureza entre os universitários, principalmente 
sobre problemas relacionados às questões ambientais, sociais e políticas, causa grandes preocupações. Essa observação foi contatada numa pesquisa há poucos anos atrás (SHEPARDSON. et al., 2011).

No presente estudo, os graduandos do curso de Educação Física responderam questões para de certa forma demonstrar seu interesse e preocupação com as alterações climáticas. Sobre a perspectiva de interesse, os alunos se mostraram bem divididos nas argumentações sendo que a metade considera o tema de muita importância e a outra metade de pouco importância. Porém, esse número é modificado quando se fala em termos de importância, nesse caso a maioria (77\%) apontou o tema como relevante. Para os graduandos, além de ser um tema de muita importância, se trata também de um tema de grande preocupação, demonstrado nos resultados com valores bem parecidos com o da questão anterior. No entanto, quando foram perguntados sobre a percepção que tinham das pessoas ao seu redor sobre o interesse em mitigar as causas das alterações climáticas, a minoria apontou que as pessoas se adaptariam e teriam ações que amenizassem as causas desse problema, já a maioria aponta que as pessoas ao seu redor teriam um esforço parcial nessa causa, e uma parcela média disse que as pessoas não fariam esforços para tentar minimizar as causas. Com essa percepção dos alunos, pode-se imaginar que apesar da importância e da preocupação do tema, o aspecto cultural e educacional do brasileiro ainda impede a demonstração de mais interesse pelo tema e mudança de comportamento no enfrentamento das causas das alterações climáticas. Quando questionados a respeito de um possível apoio por medidas que reduzissem a emissão de gases do efeito estufa, mesmo que implicasse em aumento do preço dos combustíveis, energia elétrica e outras fontes, quase metade dos alunos se mostraram positivos a mudança mesmo que isso refletisse numa carga um pouco maior da situação econômica deles. Já a outra metade ficou dividida com uma resposta negativa a essa questão ou não sabia opinar com clareza.

No trabalho de Santos et al. (2016), ele percebe que o interesse e a preocupação pelo tema das alterações climáticas entre os estudantes é maior que da população geral, mostrando a importância do acesso ao conhecimento na formação de opinião. Por outro lado, o autor acreditava que pelo maior nível de interesse dos alunos pudesse haver de forma proporcional o interesse por ações de mitigação das causas das alterações climáticas, o que não aconteceu, percebeu-se tanto na porcentagem de responder positivamente quanto nas ações especificas para minimizar as causas das mudanças. Assim, notou-se que nem sempre o interesse e a preocupação andam juntos as ações que permitem tais benefícios.

Para Harker-Schuch, o conhecimento é o motivador das mudanças de comportamento, que permite mudanças e para a criação de políticas de mitigação e adaptação às alterações climáticas. O conhecimento massivo permite que haja compreensão e compartilhamento de informações que resulte no cultivo significativo da opinião pública. Além disso, percebeu-se que somente 
o conhecimento não traria ações efetivas no combate ou na mitigação das alterações climáticas, foi constatado que ainda existiam barreiras para que acontecesse essas mudanças de comportamento efetivo (HARKER-SCHUCH; BUGGE-HENRIKSEN, 2013).

Os resultados acima reforçam a crença de que somente o conhecimento não é capaz de mudar o comportamento das pessoas, isso pode ser percebido quando os alunos tiveram que apontar quem devia tomar as ações principais para minimizar as alterações climáticas. Nessa questão os alunos ficaram bem divididos, quase a metade dos entrevistados apontou que o dever é dos governos. Outra parte que se aproxima da segunda metade apontou que as iniciativas deveriam partir dos indivíduos que compõem a sociedade, e a minoria apontaram que essas ações deveriam partir de empresas privadas. Essa boa distribuição das respostas pode apontar duas maneiras de interpretação. A primeira sobre a importância do governo nas principais ações de mitigação das alterações climáticas; que pode ocorrer pela forma que as informações chegam as pessoas através dos principais meios de comunicação, onde as informações sobre esse tema abordam com frequência medidas de governos nacionais $e$ relação intergovernamental para ações globais. A segunda maneira a se pensar, no momento que julgam a principal responsabilidade de ações partindo da população; pode-se entender que há uma espécie de conhecimento pré-formado através de medidas educativas (principalmente nos ensinos infantil e fundamental) onde estimulam o empoderamento para tomar algumas ações benéficas para a sociedade e o pensamento de que o cidadão tem seus direitos garantidos, porém possui também deveres perante a sociedade e temas que reflitam na saúde e organização social.

O conhecimento do público em geral é muito influenciado pela forma que a mídia costuma tratar os temas em suas matérias, essas abordagens afetam a maneira de pensar, principalmente do público não especializado (KRAKER; KUIJS, 2014). Em Portugal, os estudantes acreditam que as ações devam ser de iniciativa governamental, o autor do trabalho destaca como razão dessa resposta a maneira que a mídia local trata o assunto para a população, sempre focando na geografia exótica de Portugal, principalmente por regiões polares, as pequenas ilhas e a biodiversidade (CARVALHO et al., 2014; SANTOS et al., 2016).

O engajamento dos cidadãos em relação às alterações climáticas parece ser bastante limitado, e percebeu-se que a adesão a ações que mitigassem as alterações eram a economia de energia elétrica em casa e reciclagens, que foram consideradas as principais ações. Comumente entre as pessoas, foi relatado que eles trocaram as lâmpadas. Quando foram questionados sobre o porquê de não mudar mais ou realizar mais ações sobre as alterações climáticas os entrevistados relataram o alto custo financeiro e a falta de tempo, disseram também que a falta de informação também foi uma barreira a ser enfrentada nesse processo (CABECINHAS; LÁZARO; CARVALHO, 2008). 
$\mathrm{Na}$ presente pesquisa, os alunos foram questionados sobre a influência da ação humana nesse processo de alterações climáticas, a maioria dos alunos (95\%) apontou que essas mudanças estão acontecendo por influência das ações humanas no ambiente. Quando perguntados sobre seu posicionamento em relação ao conhecimento desse tema, $97 \%$ das pessoas se consideram com um conhecimento insuficiente e que necessitam de mais informações. Desses $97 \%, 36 \%$ necessitam de muito mais informações, $40 \%$ de mais informações e $21 \%$ de um pouco mais de informações. Sobre a importância desse conhecimento na carreira profissional desses futuros educadores físicos, $38 \%$ deles afirmam que esse conhecimento é de muita importância, $44 \%$ dizem que é de moderada importância e 15\% dizem ser de pouca importância.

As condições climáticas ou ambientais, exercem um efeito significativo sobre a capacidade e performance dos seres humanos tanto em repouso quanto em exercício de modo geral, esses efeitos podem colocar a saúde dos praticantes em risco, uma vez que o treinador não conhece a influência das alterações climáticas e ambientais sobre os componentes fisiológicos do seu aluno. Então, torna-se imprescindível obter o conhecimento das diversas variáveis que compõem o clima, com o intuito de identificar seus efeitos sobre os sistemas fisiológicos e, principalmente, antecipar e evitar possíveis riscos que o ambiente ou clima podem oferecer a saúde e a integridade física dos indivíduos (GARCIA; RODRIGUES, 1998). As variações de temperatura associadas às variações da umidade relativa do ar são descritas como responsáveis diretos pelo comprometimento do sistema respiratório e cardiovascular durante o esforço físico. Sendo assim, tanto a poluição que interfere a qualidade do ar atmosférico, quanto as alterações climáticas associadas ou não podem comprometer a saúde humana, principalmente de populações mais susceptíveis como idosos e crianças (CHRISTIANE et al., 2016).

\section{Conclusão}

A percepção e compreensão das alterações climáticas dependem de fatores complexos e de diversas naturezas como por exemplo cultural, educacional, social e, até mesmo a forma como uma informação é propagada no seu meio. Partindo desse raciocínio e levando em consideração toda a complexidade do tema, é necessário que haja um engajamento desse conteúdo no meio educacional, iniciando no ensino básico e se estendendo até o ensino superior. Esse engajamento e estímulo de conhecimento dessas mudanças permite a revolução cultural, no sentido de mudança na forma de encarar as alterações climáticas criando hábitos menos agressivos ao meio ambiente e tornando as pessoas mais ativas no propósito de mitigar os efeitos dessas alterações. Sob outra perspectiva, é possível afirmar que a formação profissional dos educadores físicos envolve diversas atividades que o estimulam fisicamente, gerando atividades e com isso chega-se a um resultado benéfico para a saúde e qualidade de vida do indivíduo e sociedade. E, na maioria das vezes, esse 
esforço ocorre em ambientes abertos, sofrendo ações diretas do clima (frio, calor, variações umidade, má qualidade do ar, etc.), esses fatores quando não são bem compreendidos pelo profissional responsável pela condução, planejamento e execução da prática física pode acarretar em riscos adicionais ou até mesmo comprometer a saúde e o bem estar desses praticantes.

Ao longo dos resultados, pode-se observar que os graduandos afirmaram não haver abordagem do tema de forma satisfatória; demonstraram a necessidade de mais informações, além de julgar o conteúdo de grande importância para a prática profissional. Sabe-se hoje, que o Educador Físico representa um profissional de grande valor e responsabilidade para a promoção da saúde e prevenção de doenças na sociedade; levando isso em consideração é necessário que esse mesmo profissional que muitas vezes atua com um público diversificado e que propõe buscar a melhora global do organismo através do esforço físico, atenda os indivíduos com competência não somente no domínio técnico ligado ao esforço, mas também em conhecimentos ligados as condições climáticas e ambientais, que direta ou indiretamente afetam seus clientes.

\section{Referências}

BACCINI, M. et al. Heat effects on mortality in 15 European cities. Epidemiology (Cambridge, Mass.), v. 19, n. 5, p. 711-719, 2008.

BRASIL. As cartas de promoção da saúde. In: Ministério da Educação. [s.l: s.n.]. v. 53p. 1-30, 2002.

CABECINHAS, R.; LÁZARO, A.; CARVALHO, A. Media uses and social representations of climate change. Communicating Climate Change: Discourses, Mediations and Perceptions. Braga: Centro de Estudos de Comunicacao e Sociedade, Universidade do Minho, p. 170-189, 2008.

CARVALHO, A. et al. Climate change research and policy in Portugal. WIREs Clim Change, v. 5, p. 199-217, 2014.

CHRISTIANE, W. et al. Variáveis ambientais e níveis de monóxido de carbono exalado e carboxihemoglobina em idosos praticantes de exercício. Ciência \& Saúde Coletiva, v. 1023-1032, n. 21 (4), p. 1023-1032, 2016.

COELHO, C. A. et al. A Percepção Social Das Alterações Climáticas E Do Risco De Cheia. $7^{\circ}$ Congresso da Água, p. 13, 2004.

CORTESE, T. T. P. Avaliação da política pública municipal Mudanças Climáticas na Cidade de São Paulo. [s.l.] Universidade de São Paulo, 2013.

FERREIRA NETO, J. L. et al. Processos da construção da Política Nacional de Pro-moção da Saúde. Caderno Saúde Pública, v.29, n.10, p. 1997-2007, 2013.

FLEGEL, M. J. Primeiros socorros no esporte: o mais prático guia de primeiros socorros para o esporte. [s.I.] Manole, 2002. 
GARCIA, E. S.; RODRIGUES, L. O. C. Hipertermia durante a pratica de exercicios fisicos: riscos, sintomas e tratamento. Revista Brasileira de Ciências do Esporte, v. 19, n. 3, p. 85-94, 1998.

GASPARRINI, A. et al. Mortality risk attributable to high and low ambient temperature : a multi-country study. The Lancet, v. 44, n. 0, 2015.

GUYTON, A. C.; HALL, J. E.; GUYTON, A. C. Tratado de fisiologia médica. 11. ed. [s.l.] Elsevier Brasil, 2006.

HARKER-SCHUCH, I.; BUGGE-HENRIKSEN, C. Opinions and Knowledge About Climate Change Science in High School Students. AMBIO. KUNGL. VETENSKAPS AKADEMIEN, v. 42, n. 6, p. 755-766, 2013.

HEIDMANN, I. T. S. B. et al. Promoção à saúde: trajetória histórica de suas concepções. Texto \& Contexto - Enfermagem, v. 15, n. 2, p. 352-358, 2006.

HILLMAN, S. K. Avaliação, prevenção e tratamento imediato das lesões esportivas. [s.I.] MANOLE, 2002.

JACOBI, P. R. et al. Mudanças climáticas globais: a resposta da educação. Revista Brasileira de Educação, v. 16, n. 46, p. 135-148, 2011.

KRAKER, J. DE; KUIJS, S. Internet public opinion on climate change: a world views analysis of online reader comments. International Journal of Climate Change Strategies and management, v. 6, n. 1, p. 19-33, 2014.

LEE, I.-M. et al. Impact of Physical Inactivity on the World's Major NonCommunicable Diseases. Lancet, v. 380, n. 9838, p. 219-229, 2012.

MALTA, D. C. et al. A Política Nacional de Promoção da Saúde e a agenda da atividade física no contexto do SUS. Epidemiol. Serv. Saúde, v. 18, n. 1, p. 7986, 2009.

MALTA, D. C. et al. Tendências dos indicadores de atividade física em adultos: Conjunto de capitais do Brasil 2006-2013. Rev Bras Ativ Fis Saude, v. 20, n. 2, p. 141-151, 2015.

MALTA, D. C. et al. Política Nacional de Promoção da Saúde (PNPS): capítulos de uma caminhada ainda em construção. Ciência \& Saúde Coletiva, v. 21, n. 6, p. 1683-1694, 2016.

MCARDLE, W. D.; KATCH, F. I.; KATCH, V. L. Fisiologia do exercício: nutrição, energia e desempenho humano. Rio de Janeiro: Guanabara Koogan. 2011: [s.n.].

MCMICHAEL, A. J. Globalization, Climate Change, and Human Health. The new engl and journal of medicine, p. 1335-1343, 2013.

MORGADO, F. et al. Assessing University Student Perceptions and Comprehension of Climate Change (Portugal, Mexico and Mozambique). International Journal of Climate Change Strategies and management, p. 22, 2016. 
NIGATU, A. S.; ASAMOAH, B. O.; KLOOS, H. Knowledge and perceptions about the health impact of climate change among health sciences students in Ethiopia : a cross-sectional study. BioMed Central Public Health, 2014.

RDEVELOPMENT, C. TEAM 2011: R: A Language and Environment for Statistical Computing. Vienna: R Foundation for Statistical Computing, 2013.

REAY, D. et al. Intergovernmental Panel on Climate Change. Fourth Assessment Report. Geneva, Switzerland: Inter-gov- ernmental Panel on Climate Change. Cambridge; UK: Cambridge University Press; 2007. Available from: www. ipcc.ch.Intergovernmental Panel on Climate Change. 2016

SANTOS, P. T. et al. Assessing Student Perceptions and Comprehension of Climate Change in Portuguese Higher Education Institutions. In: 2016. p. 221-236.

SHEPARDSON., D. P. et al. Student Conceptions about Global Warming and Climate Change. Global Warming and Climate Change, v. 104, n. 3, p. 481507, 2011.

SOUZA, E. C. DE et al. Impactos das mudanças climáticas sobre o bem-estar relacionado à saúde no Brasil. Pesq e Planej Econ., v. 43, n. 1, p. 49-8, 2013.

STAMATAKIS, E. et al. The Influence of Global Heating on Discretionary Physical Activity: An Important and Overlooked Consequence of Climate Change. Journal of Physical Activity \& Health, v. 10, p. 765-768, 2013.

VIEGAS, V. et al. Alterações Climáticas, Perceções e Racionalidades. Journal of Integrated Coastal Zone Management, v. 14, n. 3, p. 347-363, 2014. 